\title{
Distribuição de Sistemas Agroflorestais no Estado De São Paulo: apontamentos para restauração florestal e produção sustentável
}

\author{
ADRIANA CAVALIERI SAIS \\ Universidade Federal de São Carlos \\ RENATA EVANGELISTA DE OLIVEIRA \\ Universidade Federal de São Carlos
}

\begin{abstract}
Resumo
Este trabalho teve como principal objetivo uma análise descritiva da distribuição espacial de sistemas agroflorestais no Estado de São Paulo, a partir de informações disponibilizadas pelo Censo Agropecuário de 2006. Partindo-se da distribuição apresentada por esses sistemas, buscamos discutir sua adoção e relação com o uso do solo em diferentes regiões, bem como discorrer sobre seu potencial como sistemas de produção e de restauração em áreas protegidas na paisagem rural do estado. Os resultados apontam uso incipiente dos Sistemas Agroflorestais à época do levantamento, e concentração dos mesmos em regiões específicas, com destaque a alguns municípios. Isso provavelmente está associado à concentração de assentamentos rurais e pequenas propriedades, à adequação de áreas de preservação permanente e reservas legais e ao interesse na implantação de modelos agroflorestais de produção com algumas espécies (principalmente exóticas) em particular. Palavras-chave: Análise espacial. SAFs. Censo agropecuário. Paisagem rural. Políticas públicas. Agricultura familiar.
\end{abstract}

Distribution of Agroforestry Systems in the State of São Paulo: possibilities for forest restoration and sustainable production

\footnotetext{
Abstract

The aim of this study was to make a descriptive analysis of the spatial distribution of agroforestry systems in the State of São Paulo, based on information provided by the 2006 Agricultural Census. Based on the distribution presented by these systems, we discuss their adoption and relationship with land use in different regions, as well as their potential as production and restoration systems in protected areas in the rural landscape of the state.
} 
The results show an incipient use of AFs at the time of survey, and their concentration in specific regions, with emphasis on some municipalities. This is probably associated to the concentration of rural settlements and small properties, to the compliance of permanent preservation areas and legal reserves, and to the interest in establishing agroforestry models of production with some species (mainly exotic) in particular.

Keywords: Spacial analysis. AFs. Agricultural Census. Rural landscape. Public policies. Family agriculture.

\title{
Distribución de sistemas agroflorestais en el Estado de São Paulo: apuntes para restauración florestal y producción sostenible
}

\begin{abstract}
Resumen
Este trabajo tuvo como principal objetivo un análisis descriptivo de la distribución espacial de sistemas agroforestales en el Estado de São Paulo, a partir de informaciones del Censo Agropecuario de 2006. Partiendo de la distribución presentada de esos sistemas, buscamos discutir su adopción y relación con el uso del uso suelo en diferentes regiones, así como discurrir sobre su potencial como sistemas de producción y de restauración en áreas protegidas en el paisaje rural del estado. Los resultados apuntan uso incipiente de los SAFs a la época del levantamiento, y concentración de los mismos en regiones específicas, con destaque a algunos municipios. Esto probablemente se debe a la concentración de asentamientos rurales y pequeñas propiedades, a la adecuación de áreas de preservación permanente y reservas legales y al interés en la implantación de modelos agroforestales de producción con algunas especies (principalmente exóticas).
\end{abstract}

Palabras-clave: Análisis espacial. SAFs. Censo agropecuario. Paisaje rural. Políticas públicas. Agricultura familiar.

\section{Introdução}

Sistemas agroflorestais-SAFs são sistemas de uso da terra em policultivo ou de cultivo múltiplo (SOMMARIBA, 1992) em que plantas lenhosas perenes são manejadas em associação com plantas herbáceas, arbustivas, arbóreas, culturas agrícolas, forrageiras e/ou em integração com animais, em uma mesma unidade de manejo, de acordo com arranjo espacial e temporal, com alta diversidade de espécies e interações entre estes componentes (SÃO PAULO, 2008; BRASIL, 2012). O consórcio de espécies pode ser simultâneo ou em uma sequência temporal (MONTAGNINI, 1992; ABDO et al., 2012) e envolver os mais variados modelos (NAIR, 1993; MAY e TROVATTO, 2008; VIVAN, 1993; VIVAN, 1998). Práticas agroflorestais também envolvem a incorporação de culturas já domesticadas no enriquecimento de ambientes naturais, como capoeiras ou florestas nativas (HENKEL e AMARAL, 2008).

A diversidade, composição, disposição e alocação de espécies são muito variáveis, e existem formas mais ou menos intensivas de manejo desses sistemas, baseadas principalmente em seus níveis de diversidade e complexidade. Os SAFs têm sido apontados como ferramentas interessantes no que tange à reintrodução do componente arbóreo na paisagem rural, que pode ter objetivos ecológicos (como a melhoria de conectividade na paisagem, resgate da biodiversidade nativa e serviços ecossistêmicos) ou econômicos (em que se enfoca a obtenção de produtos agrícolas e florestais madeireiros e não madeireiros com vistas à geração de emprego e renda nas propriedades rurais) (MONTAGNINI et al., 2005; SCHROTH et 
al., 2007; OLIVEIRA et al., 2008). Desde que bem planejados, desenhados e conduzidos, podem subsidiar a adequação legal de propriedades rurais no que tange à presença do componente florestal, e se tornarem alternativas viáveis de geração de renda aliadas à melhoria da paisagem, restauração de ecossistemas florestais e à conservação da agrossociobiodiversidade.

A paisagem rural do Estado de São Paulo é bastante heterogênea, no que diz respeito à sua cobertura vegetal nativa, usos do solo e organização/distribuição de propriedades rurais. Sua cobertura vegetal nativa abriga fitofisionomias dos biomas Mata Atlântica e Cerrado (KRONKA et al., 2005), distribuídas na paisagem de forma desordenada e fragmentada.

Diversos são os tipos de SAFs apontados como aplicáveis às condições de São Paulo, englobando sistemas agroflorestais sequenciais e simultâneos, de dossel fechado ou aberto. Alguns modelos já descritos como experiências em andamento em localidades diversas incluem capoeiras melhoradas, agroflorestas sucessionais, sistemas taungya, SAFs em aleias, quintais agroflorestais ou hortos caseiros, árvores em associações com cultivos perenes e anuais diversos (como cafezais sombreados, citricultura agroflorestal, sistemas silvipastoris, consórcios com seringueira e SAFs multiestratificados), além de cercas vivas e quebra-ventos. Esses modelos buscam a atender tanto aos objetivos de produção e geração de renda quanto de conservação e restauração, em áreas protegidas (unidades de conservação, reservas legais e áreas de preservação permanente) ou não (ENGEL, 1999; JÚNIOR et al., 2004; JÚNIOR et al., 2007; MAY e TROVATTO, 2008; RODRIGUES et al., 2008; VALENTINI et al., 2010; DARONCO et al., 2012; STEENBOCK et al., 2013; JUNQUEIRA et al., 2013; DONATO e LIMA, 2014; SOUZA e PIÑA-RODRIGUES, 2013).

A distribuição espacial dos SAFs em uma paisagem certamente denota sua aceitação (ou não) por agricultores e pode estar relacionada a fatores históricos, sociais, culturais (como formas de uso e manejo tradicionais) econômicos (de diferentes comunidades e agricultores) ou a políticas públicas que estimulem sua adoção e implantação.

Não existem, atualmente, políticas públicas específicas para o estímulo da adoção de sistemas agroflorestais na paisagem, mas várias políticas nacionais são voltadas à diversificação da produção pela agricultura familiar.

Podem ser citadas as políticas de compras governamentais que emergiram a partir dos anos 2000, tais como: o Programa Nacional da Alimentação Escolar-PNAE e o Programa de Aquisição de Alimentos- PAA - que trouxeram oportunidades significativas de acesso a mercados para agricultores familiares em diversas regiões do Brasil - e o Programa Nacional de Fortalecimento da Agricultura FamiliarPRONAF (COSTA et al., 2015, SOUZA-ESQUERDO e BERGAMASCO, 2015). Para essas autoras, o PAA alia a política agrícola, enfocando a questão da comercialização, à segurança alimentar e nutricional da população.

Entre aqueles que acessam essas políticas estão extrativistas e agroextrativistas e agricultores familiares cujos produtos comercializados advém de espécies florestais (em remanescentes de vegetação natural e em plantios florestais e agroflorestais).

Com vistas à adequação ambiental das atividades desenvolvidas em pequenas propriedades rurais, o manejo em modelos agroflorestais também é regulamentado pela legislação (OLIVEIRA e SAIS, 2017). 
A descrição da distribuição espacial dos SAFs na paisagem permite discutir sua adoção e relação com o uso do solo em diferentes regiões, apontando seu potencial como sistema de produção e de restauração florestal.

Esta pesquisa tem por objetivo realizar uma análise descritiva da organização espacial da variável geográfica apresentada por sistemas de uso do solo caracterizados como agroflorestais nos municípios do Estado de São Paulo a partir de informações do Censo Agropecuário 2006 (IBGE, 2007).

\section{Material e métodos}

A localização de SAFs no Estado de São Paulo foi obtida a partir de dados do Censo Agropecuário de 2006. Mais especificamente, foram analisadas as informações referentes às áreas descritas no levantamento como SAFs, ou seja, áreas florestais usadas para lavouras e pastejo de animais. Foram utilizadas as informações sobre utilização das terras nos estabelecimentos agropecuários, agrupados por município, microrregião e mesorregião (IBGE, 2007).

As informações tabulares foram organizadas em planilha eletrônica de modo a permitir a união com mapa de municípios da base cartográfica contínua do Brasil ao milionésimo (IBGE, 2014), disponível em formato para utilização em Sistema de Informação Geográfica no sítio do Instituto Brasileiro de Geografia e EstatísticaIBGE.

O software utilizado para a manipulação de dados e informações espaciais foi o QGIS. Nele, no arquivo de limite de municípios da base cartográfica, foram recortados aqueles pertencentes ao Estado de São Paulo. Esses municípios foram agrupados por meso e microrregião, criando três planos de informação espacial.

As tabelas do IBGE (em formato Microsoft Excel) foram introduzidas na plataforma QGIS por meio do complemento "Spreadsheet Layers", e unidas espacialmente com os respectivos municípios no Estado de São Paulo, utilizando o comando "união", na janela "propriedades" desse plano de informação. Os mesmos procedimentos foram realizados para as meso e microrregiões.

Para a análise descritiva da variável geográfica (SAFs) distribuída em mapa poligonal (municípios), utilizou-se técnica de classificação de dados que permite o agrupamento em classes de valores, que na imagem gráfica resultante (em mapa) torna possível a análise exploratória, identificando relações de vizinhança, contiguidade e agregação espacial. A técnica de grupamento utilizada para as variáveis analisadas foi a de intervalos iguais, que se baseia no fatiamento da série em classes de valores com larguras iguais. Nesse método os valores são colocados em ordem crescente, calcula-se a amplitude e divide-se pelo número de classes.

Para este estudo, foram analisadas duas variáveis: número de estabelecimentos com SAFs e área ocupada com SAFs nas três escalas (mesorregião, microrregião e municípios).

A partir de cada conjunto de dados nessas escalas, foram estabelecidas cinco classes de intervalos iguais para as duas variáveis, partindo do menor para o maior valor: Classe 1 = muito baixo; Classe 2 = baixo; Classe $3=$ médio; Classe $4=$ alto; Classe 5 = muito alto.

Os mapas gerados foram avaliados por análise visual, considerando a localização geográfica nas três escalas, com vistas a permitir uma interpretação 
Distribuição de Sistemas Agroflorestais no Estado De São Paulo: apontamentos para restauração florestal e produção sustentável

sobre a espacialização dos SAFs na paisagem e confrontá-la com dados históricos, e de incentivos à sua adoção.

\section{Resultados e discussão}

Os SAFs aparecem pela primeira vez no censo agropecuário realizado pelo IBGE no levantamento de 2006. O levantamento não tipifica os SAFs nos diferentes municípios em termos dos modelos ou composição de espécies. O critério de inclusão é bem amplo, abrange todas as "áreas ocupadas com sistema agroflorestal de produção, baseado em consórcios ou combinações de espécies florestais variadas (árvores ou palmáceas), produtivas ou não, com agricultura diversificada e/ou criação de animais, normalmente de forma intensiva e em escala reduzida" (IBGE, 2007).

O número de estabelecimentos com SAFs em 2006 era de 4.292 no Estado de São Paulo, totalizando $117 \mathrm{mil}$ ha. Isso significa que apenas $1,9 \%$ dos estabelecimentos agropecuários tinham, à época, SAFs instalados (equivalentes a $0,7 \%$ da área total do estado).

\subsection{Distribuição de Sistemas Agroflorestais nas meso e microrregiões}

O Estado de São Paulo é dividido pelo IBGE em 15 mesorregiões geográficas, subdivididas em 63 microrregiões, com identidades regionais características e múltiplas especificidades de cunho socioeconômico, ambiental e de articulação espacial. Distribuídos nessas regiões, o Estado tem 227.622 estabelecimentos rurais, perfazendo uma área total aproximada de 17 milhões de ha. Estabelecimentos rurais ou agropecuários são definidos como toda unidade de produção dedicada, total ou parcialmente, a atividades agropecuárias, florestais e aquícolas, subordinada a uma única administração, do produtor ou de administrador (IBGE, 2007).

O número de estabelecimentos com SAFs nas mesorregiões variou de 48 a 692. Sua distribuição geográfica é apresentada na Figura 1. Itapetininga é a mesorregião com maior número de estabelecimentos com SAFs, com 692 (Classe 5), seguida da mesorregião de São José do Rio Preto, com 467 (Classe 4). Em uma faixa intermediária, estão outras cinco mesorregiões, pertencentes à Classe 3, distribuídas em um eixo leste-oeste(Presidente Prudente, Bauru, Campinas, Macro Metropolitana Paulista e Vale do Paraíba Paulista). 
Figura 1. Distribuição geográfica das mesorregiões do Estado de São Paulo agrupadas em cinco classes de intervalos iguais, do número de estabelecimentos com sistemas agroflorestais

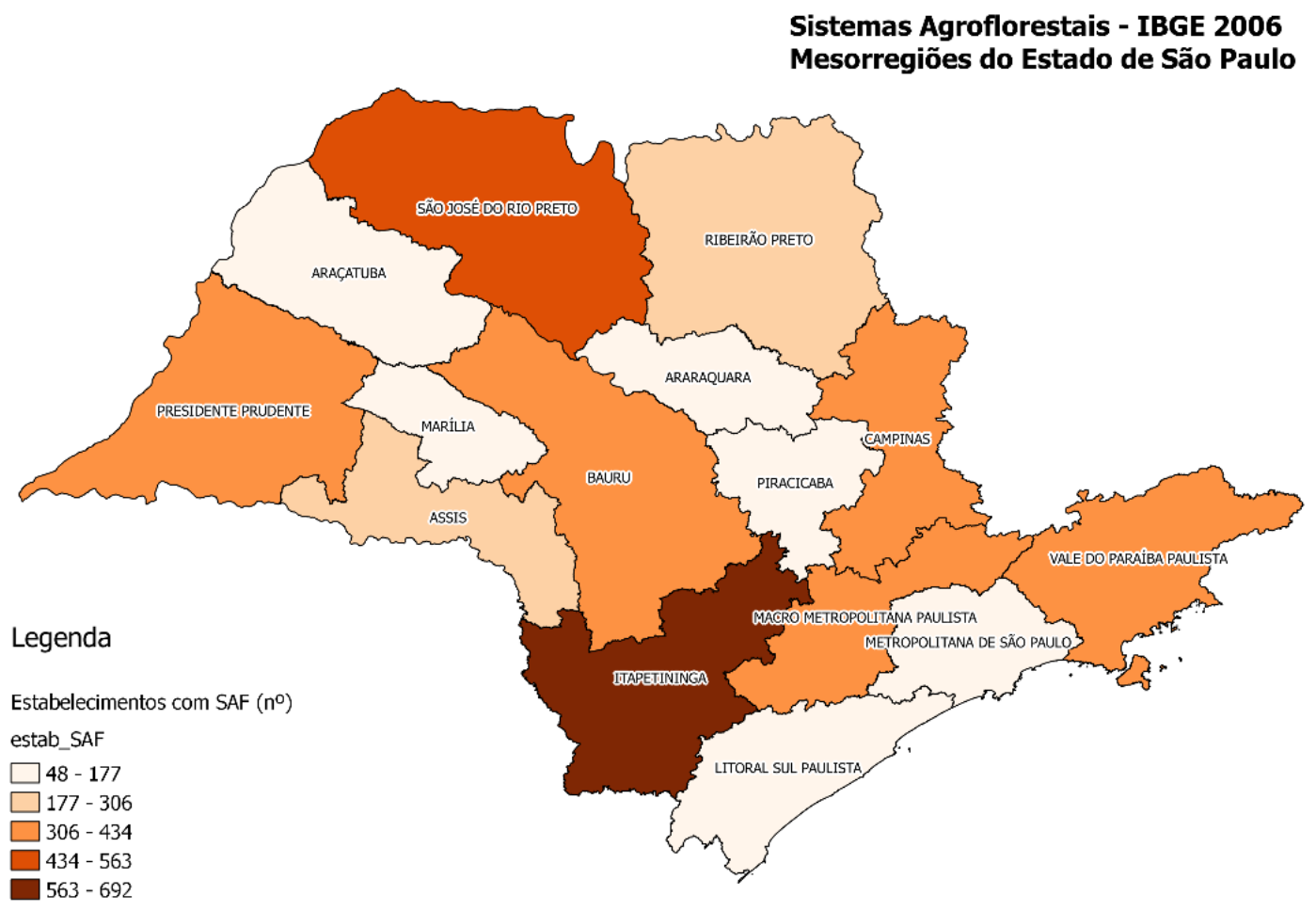

Fonte: Censo Agropecuário de 2006 do IBGE.

Quando se analisa a área ocupada por SAFs, classificada por mesorregião (Figura 2), a distribuição apresenta-se bem diferente. A maior área ocupada por SAFs é a região de Bauru (Classe 5), com 24.123 ha, seguida de Itapetininga (Classe 4), com 16.501 ha.

O menor número de estabelecimentos com SAFs e a menor área de SAFs são observados nas mesorregiões de Marília, Araraquara, Piracicaba, Litoral Sul Paulista e Metropolitana de São Paulo (todas da Classe 1), e aparentemente não existe uma relação geográfica entre elas. 
Distribuição de Sistemas Agroflorestais no Estado De São Paulo: apontamentos para restauração florestal e produção sustentável

Figura 2. Distribuição geográfica das mesorregiões do Estado de São Paulo agrupadas em cinco classes de intervalos iguais da área ocupada com sistemas agroflorestais

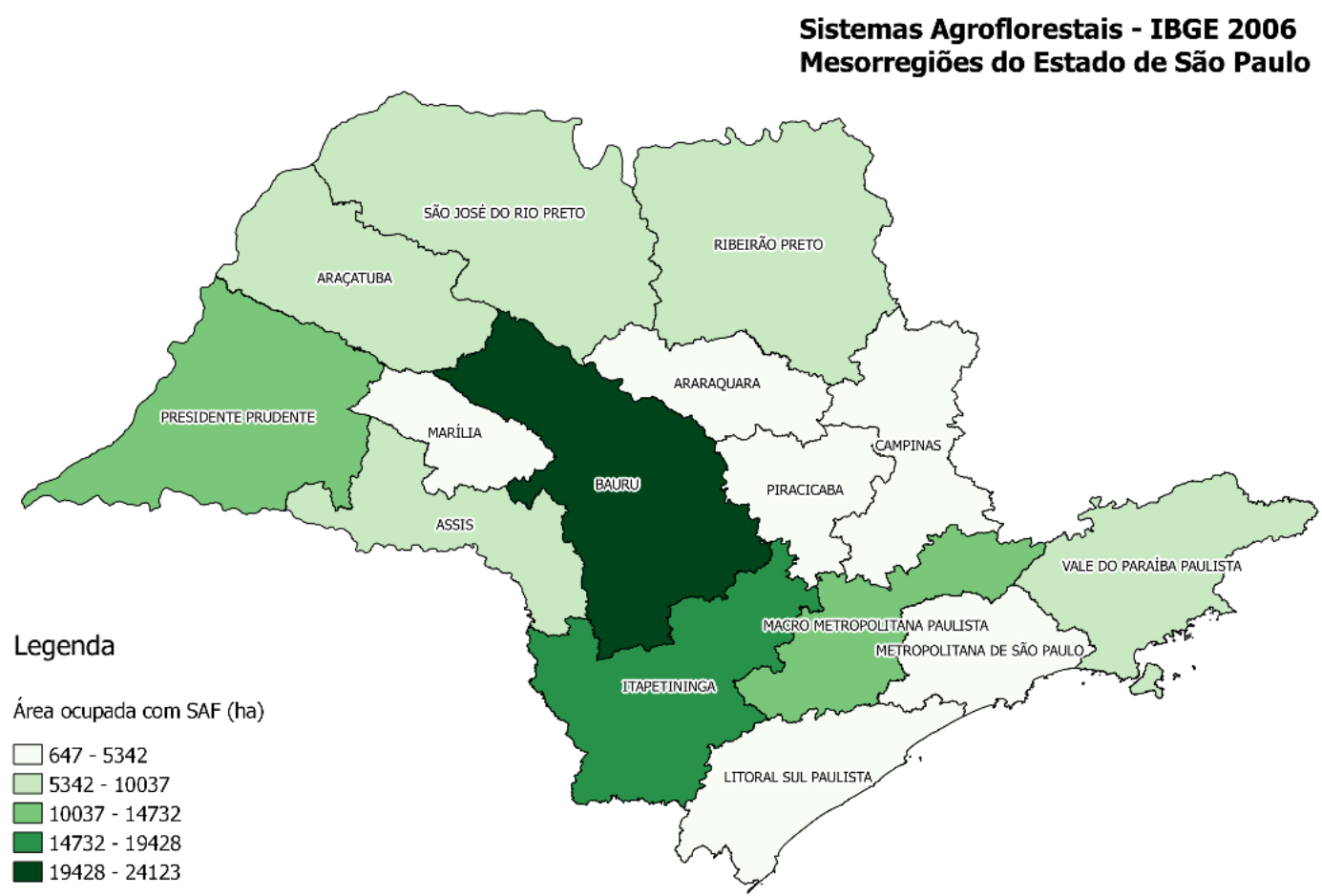

Fonte: Censo Agropecuário de 2006 do IBGE.

A distribuição do número de estabelecimentos com SAFs por microrregião (Figura 3) permite uma análise mais detalhada dessa variável, e demonstra que a concentração de SAFs nas mesorregiões, na realidade, é resultado do alto número de estabelecimentos em microrregiões específicas.

Por exemplo, na mesorregião de Presidente Prudente, a microrregião de mesmo nome é que tem alta concentração de SAFs (presentes em 307 estabelecimentos, identificando-a como da Classe 5), enquanto que as microrregiões de Adamantina e Dracena têm, respectivamente, 44 e 26 estabelecimentos com SAFs (pertencem à Classe 1).

Outra microrregião de destaque (na Classe 5) é Capão Bonito, que pertence à mesorregião de Itapetininga, com 373 estabelecimentos com SAF. Nessa mesma mesorregião, destaca-se ainda a microrregião de Itapeva, com 207 estabelecimentos. Já Itapetininga pertence à Classe 2 (com 79), enquanto que Tatuí tem somente 33 estabelecimentos com SAF, enquadrando-se na Classe 1. 
Figura 3. Distribuição geográfica das microrregiões do Estado de São Paulo agrupadas em cinco classes de intervalos iguais, do número de estabelecimentos com sistemas agroflorestais

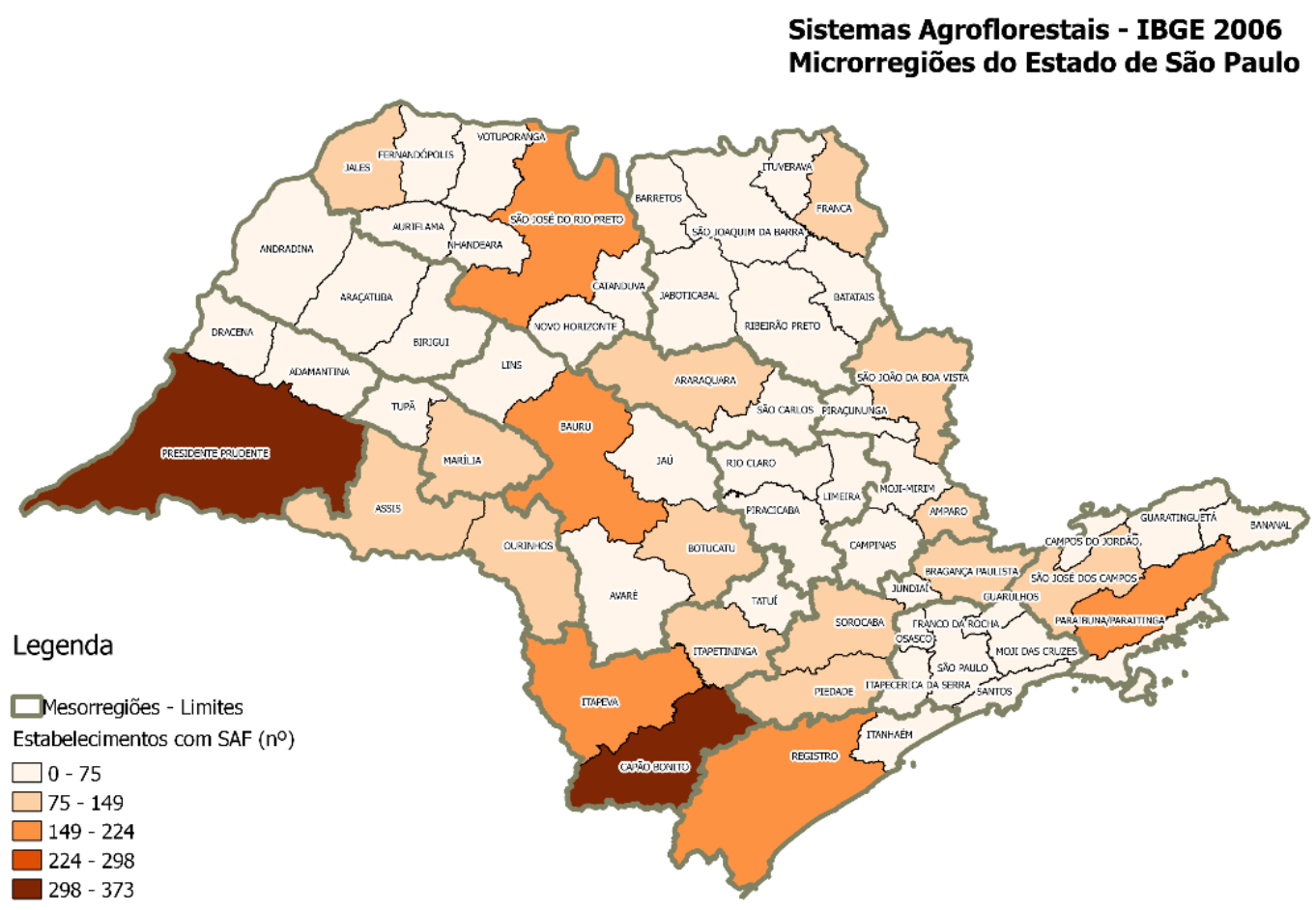

Fonte: Censo Agropecuário de 2006 do IBGE.

A figura 4 representa a área ocupada com SAFs por microrregião e nela pode ser observado que a região de Presidente Prudente, que tem um dos mais elevados número de estabelecimentos com SAFs, também apresenta grande área ocupada por esses sistemas (Classe 5). A outra região com número elevado de SAFs é a região de Bauru (também na classe 5). Nelas, as áreas de SAFs variam de 10.103 a 12.628 ha.

Observa-se que toda a região Leste do Estado ficou classificada na faixa de valores muito baixo (Classe 1), já que nessas microrregiões as áreas de SAFs não ultrapassam 2.226 ha. 
Distribuição de Sistemas Agroflorestais no Estado De São Paulo: apontamentos para restauração florestal e produção sustentável

Figura 4. Distribuição geográfica das microrregiões do Estado de São Paulo agrupadas em cinco classes de intervalos iguais, do número de estabelecimentos e da área ocupada com sistemas

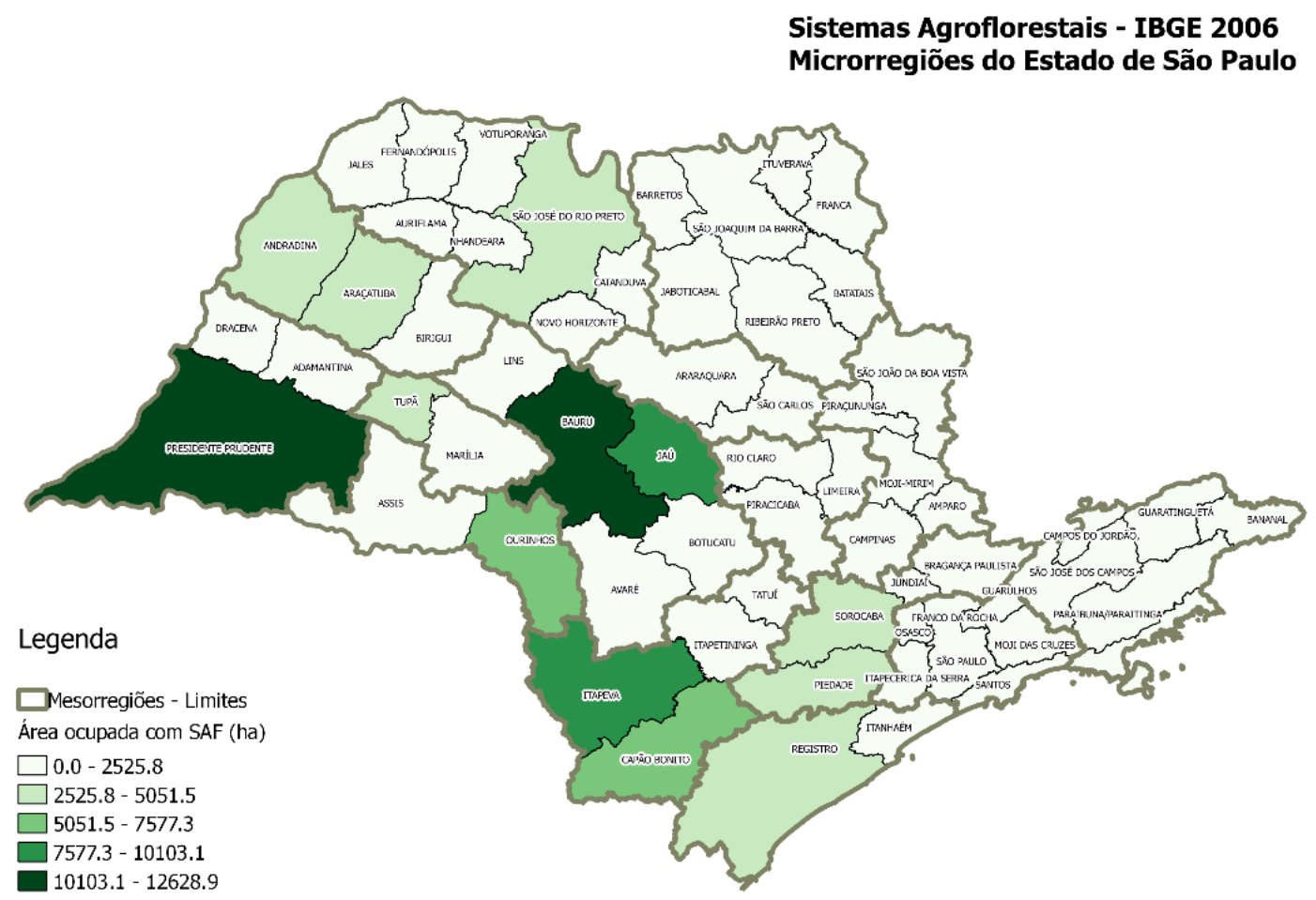

Fonte: Censo Agropecuário de 2006 do IBGE.

\subsection{Distribuição de Sistemas Agroflorestais nos municípios do Estado de São Paulo}

A distribuição e a espacialização de SAFs no Estado de São Paulo se devem ao contexto histórico de ocupação da agricultura, à tradição de algumas culturas em determinadas regiões, ao atendimento a mercados locais, à adaptação de espécies a características edafoclimáticas distintas e potencialidades relacionadas à sua implantação e uso, e a outros fatores intrínsecos referentes à aceitação (ou não) desses sistemas por agricultores na paisagem rural.

A proposição e implantação de práticas agroflorestais, como a de qualquer sistema agrícola, envolvem a combinação de fatores climáticos, edáficos, topográficos e de uso da terra (PRINSLEY, 1992), mas estão também fortemente relacionadas a aspectos socioeconômicos. De acordo com Henkel e Amaral (2008), para iniciar ou manter uma produção, o agricultor avalia vários fatores, como o risco, as despesas e a mão de obra necessária, considerados fatores negativos. A facilidade de trabalhar com o sistema e a renda esperada são considerados fatores positivos. Para os autores, a avaliação do risco e a facilidade de trabalhar são aspectos não monetários e, portanto, qualitativos de percepção. 
A adoção de sistemas agroflorestais por produtores rurais é variável. Estudos apontam que a motivação para a utilização de espécies arbóreas e a escolha dessas espécies para SAFs é essencialmente econômica (SALAM et al., 2000; SIMMONS et al., 2002), relacionada à inclusão de espécies arbóreas em sistemas agrícolas de produção, em geral caracterizadas como de uso múltiplo (MARTINEZ et al., 2010; COELHO, 2012).

A escala de maior detalhe no trabalho é a escala de município, representada nas figuras 5 e 6 . Nessa escala, o número de estabelecimentos com SAFs por município variou de o a 96, enquanto que a área ocupada por SAFs variou de o ha a 8012 ha.

Figura 5. Distribuição geográfica dos municípios do Estado de São Paulo agrupados em cinco classes de intervalos iguais, do número de estabelecimentos com sistemas agroflorestais por município no estado de São Paulo

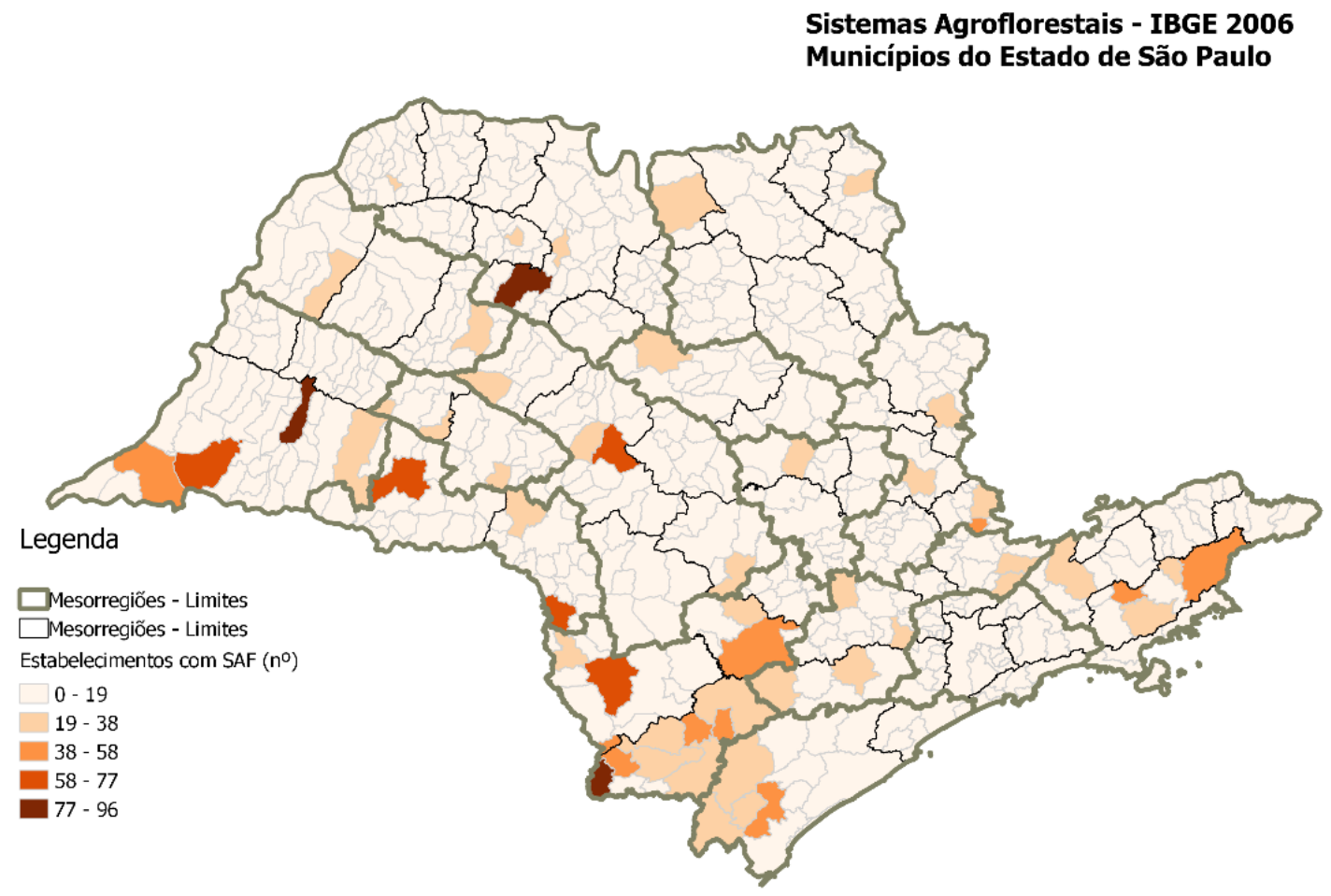

Fonte: Censo Agropecuário de 2006 do IBGE. 
Figura 6. Distribuição geográfica dos municípios do Estado de São Paulo agrupados em cinco classes de intervalos iguais, da área ocupada com sistemas agroflorestais

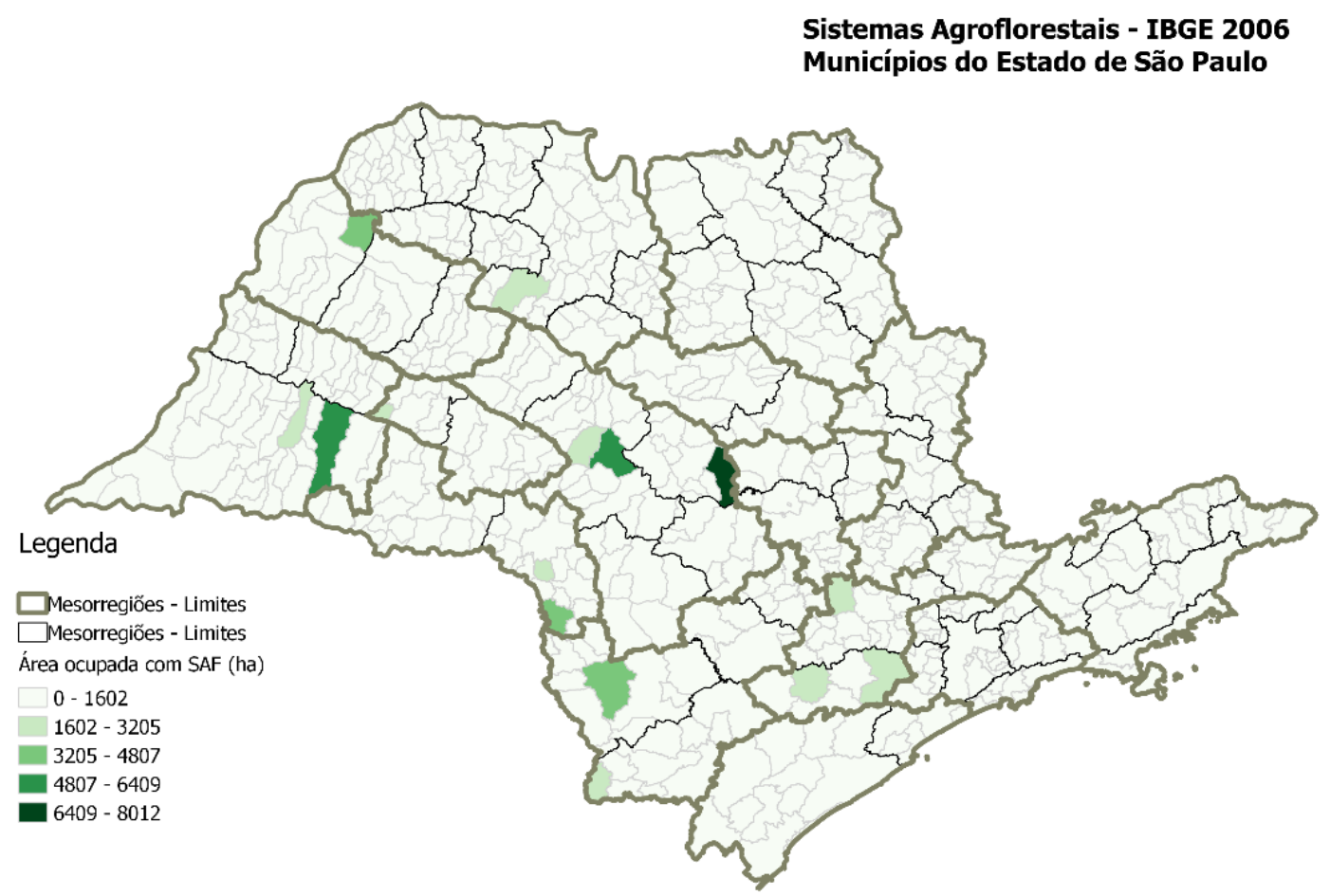

Fonte: Censo Agropecuário de 2006 do IBGE.

Pelos dados apresentados no censo, 150 dos 645 municípios do Estado não têm registro de estabelecimentos com SAFs, e 91\% deles (589) têm até 19 estabelecimentos com presença desses sistemas (Classe 1 ).

Quando se analisa a área ocupada por SAFs, 630 municípios (ou seja, 98\%) estão na Classe 1, com áreas ocupadas menores que 1602 ha. Na Classe 1, 319 municípios não apresentam áreas com SAFs, apesar de 169 deles terem registrados no Censo um ou dois estabelecimentos com SAFs.

Isso permite a suposição de que essas áreas são muito pequenas, não estando representadas na unidade utilizada no Censo (hectare) - ou seja, essas áreas, provavelmente, são menores que 1 ha, o que pode, talvez, caracterizar a ocorrência dos chamados quintais agroflorestais nesses locais.

Quintais agroflorestais (também chamados de hortos ou pomares caseiros) consistem em consórcios agroflorestais de pequenas dimensões localizados ao redor das residências, envolvendo também a criação de pequenos animais (BRITO, 2000, LUNZ, 2007). Possuem diferentes funções, como a produção de alimentos, adaptação de novas variedades de plantas, produção de matéria-prima para artesanato, cultivo de plantas medicinais e ornamentais e reciclagem de resíduos domésticos, servindo ainda como espaços de convivência (COSTANTIN, 2005). A seleção das espécies cultivadas é determinada por fatores socioeconômicos e ambientais, hábitos de dieta e demandas de mercados locais. Esse tipo de SAFs está muito relacionado à dinâmica da agricultura familiar. Pode-se supor ainda a existência de áreas muito pequenas, não registradas, pulverizadas na paisagem. 
Existem perfis de agricultores e sistemas socioculturais muito distintos na paisagem rural do Estado de São Paulo. Observam-se, nitidamente, duas situações nas quais se enquadram os municípios com SAFs: grandes áreas em um pequeno número de estabelecimentos (que supõe-se enquadradas no que se chama de agricultura patronal), e municípios com um grande número de estabelecimentos com áreas menores de SAFs, provavelmente relacionados à implantação de SAFs por agricultores familiares.

Para uma análise mais detalhada sobre os municípios cujas informações são mais relevantes, no que tange à implantação e manejo de SAFs, foram elaborados os Quadros 1 e 2, que apresentam, respectivamente, uma hierarquização dos dez municípios com os maiores números de estabelecimentos agropecuários com SAFs e com as maiores áreas totais ocupadas com esses sistemas.

Quadro 1. Municípios do Estado de São Paulo hierarquizados de acordo com o maior número de estabelecimentos com SAFs segundo dados do Censo Agropecuário de 2006 do IBGE.

\begin{tabular}{|c|l|c|c|}
\hline Posição & Município & $\begin{array}{c}\text { Número de } \\
\text { estabelecimentos } \\
\text { com SAFs }\end{array}$ & $\begin{array}{c}\text { Área ocupada por } \\
\text { SAFs (ha) }\end{array}$ \\
\hline $1^{\circ}$ & Itapirapuã Paulista & 96 & 2.321 \\
\hline $2^{\circ}$ & Presidente Prudente & 84 & 2.704 \\
\hline $3^{\circ}$ & José Bonifácio & 79 & 2.264 \\
\hline $4^{\circ}$ & Paraguaçu Paulista & 75 & 594 \\
\hline $5^{\circ}$ & Itaberá & 74 & 4.029 \\
\hline $6^{\circ}$ & Mirante do Paranapanema & 67 & 284 \\
\hline $7^{\circ}$ & Bauru & 65 & 4.845 \\
\hline $8^{\circ}$ & Fartura & 59 & 3.685 \\
\hline $9^{\circ}$ & Guapiara & 54 & 712 \\
\hline $10^{\circ}$ & Pinhalzinho & 49 & 90 \\
\hline
\end{tabular}

Quadro 2. Municípios do Estado de São Paulo hierarquizados de acordo com a maior área ocupada com SAFs, segundo dados do Censo Agropecuário de 2006 do IBGE

\begin{tabular}{|c|l|c|c|}
\hline Posição & Município & $\begin{array}{c}\text { Área ocupada por } \\
\text { SAFs }\end{array}$ & $\begin{array}{c}\text { Número de } \\
\text { estabelecimentos com } \\
\text { SAFs }\end{array}$ \\
\hline $1^{\circ}$ & Dois Córregos & 8.012 & 13 \\
\hline $2^{\circ}$ & Martinópolis & 5.831 & 7 \\
\hline $3^{\circ}$ & Bauru & 4.845 & 65 \\
\hline $4^{\circ}$ & Itaberá & 4.029 & 74 \\
\hline $5^{\circ}$ & Fartura & 3.685 & 59 \\
\hline $6^{\circ}$ & Sud Mennucci & 3.329 & 8 \\
\hline $7^{\circ}$ & Avaí & 2.740 & 23 \\
\hline $8^{\circ}$ & Presidente Prudente & 2.704 & 84 \\
\hline $9^{\circ}$ & Itapirapuã Paulista & 2.321 & 96 \\
\hline $10^{\circ}$ & José Bonifácio & 2.264 & 79 \\
\hline
\end{tabular}


Distribuição de Sistemas Agroflorestais no Estado De São Paulo: apontamentos para restauração florestal e produção sustentável

São seis os municípios que apresentam ao mesmo tempo um alto número de estabelecimentos e grandes áreas com SAFs: Itapirapuã Paulista, Presidente Prudente, José Bonifácio, Itaberá, Bauru e Fartura.

Quatro municípios apresentam áreas pequenas ocupadas com SAFs em um grande número de estabelecimentos (Paraguaçu Paulista, Mirante do Paranapanema, Guapiara e Pinhalzinho), enquanto que outros quatro (Dois Córregos, Martinópolis, Sud Mennucci e Avaí) têm grandes áreas ocupadas em um número reduzido de estabelecimentos.

O Quadro 3 apresenta o perfil agrário/fundiário dos 14 municípios, destacados nos Quadros 1 e 2.

Quadro 3. Perfil agrário/fundiário dos municípios que se destacam quanto a área e/ou número de estabelecimentos com SAFs no Estado de São Paulo, incluindo a adesão a políticas públicas voltadas à agricultura familiar - PRONAF (Programa Nacional de fortalecimento da Agricultura Familiar), PAA (Programa de aquisição de alimentos) e PNAE (Programa Nacional de alimentação escolar), com base em IBGE (2007), BRASIL (2015)

\begin{tabular}{|l|c|c|c|c|c|c|c|}
\hline \multirow{2}{*}{ Município } & \multirow{2}{*}{$\begin{array}{c}\text { Área total } \\
\text { (ha) }\end{array}$} & \multirow{2}{*}{$\begin{array}{c}\text { ER* } \\
\left(\mathrm{N}^{\circ}\right)\end{array}$} & \multirow{2}{*}{$\begin{array}{c}\text { ER AF } \\
\left(\mathrm{N}^{\circ}\right)\end{array}$} & $\begin{array}{c}\text { Famílias } \\
\text { Assentadas } \\
\left(\mathrm{N}^{\circ}\right)^{* *}\end{array}$ & $\begin{array}{c}\text { PRONAF } \\
* * *\end{array}$ & $\begin{array}{c}\text { PAA } \\
* *\end{array}$ & $\begin{array}{c}\text { PNAE } \\
* * * * *\end{array}$ \\
\hline Avaí & 54.869 & 339 & 148 & - & $\mathrm{x}$ & & $\mathrm{x}$ \\
\hline Bauru & 40.128 & 470 & 228 & 371 & $\mathrm{X}$ & & $\mathrm{x}$ \\
\hline Dois Córregos & 67.478 & 380 & 261 & - & $\mathrm{x}$ & & \\
\hline Fartura & 24.205 & 647 & 415 & - & $\mathrm{x}$ & & $\mathrm{x}$ \\
\hline Guapiara & 21.296 & 890 & 742 & - & $\mathrm{x}$ & $\mathrm{x}$ & \\
\hline Itaberá & 99.485 & 1.441 & 1.166 & 223 & $\mathrm{x}$ & $\mathrm{x}$ & $\mathrm{x}$ \\
\hline $\begin{array}{l}\text { Itapirapuã } \\
\text { Paulista }\end{array}$ & 30.619 & 335 & 259 & - & & & $\mathrm{x}$ \\
\hline José Bonifácio & 55.350 & 715 & 445 & 18 & $\mathrm{x}$ & & $\mathrm{x}$ \\
\hline Martinópolis & 135.550 & 740 & 481 & 122 & $\mathrm{x}$ & & $\mathrm{x}$ \\
\hline $\begin{array}{l}\text { Mirante do } \\
\text { Paranapanema }\end{array}$ & 97.856 & 2.282 & 1.812 & 1.587 & $\mathrm{X}$ & & $\mathrm{x}$ \\
\hline $\begin{array}{l}\text { Paraguaçu } \\
\text { Paulista }\end{array}$ & 90.283 & 663 & 383 & - & $\mathrm{x}$ & & $\mathrm{x}$ \\
\hline Pinhalzinho & 8.364 & 716 & 631 & - & $\mathrm{x}$ & & $\mathrm{x}$ \\
\hline $\begin{array}{l}\text { Presidente } \\
\text { Prudente }\end{array}$ & 33.417 & 868 & 672 & - & $\mathrm{x}$ & & $\mathrm{x}$ \\
\hline Sud Mennucci & 56.570 & 224 & 138 & - & $\mathrm{x}$ & & \\
\hline
\end{tabular}

* Dados de 2006, ** Dados de 2015, *** Dados de 2015/2016, ***** Dados de 2014

Os dados apresentados no Quadro 3 podem apontar possíveis causalidades da presença dos SAFs nesses municípios, mas não explicam os que mais se destacam quanto ao número de estabelecimentos com SAFs ou maiores áreas que comportam esses modelos.

Por exemplo, pode-se observar que não existe uma relação direta entre o número de estabelecimentos que declararam ter SAFs com o número total de estabelecimentos agrícolas do município, bem como com a quantidade de famílias assentadas. 
Entretanto, quando se calcula a porcentagem do número de estabelecimentos classificados como de agricultura familiar em relação ao total de estabelecimentos, os valores mais altos encontrados são daqueles que têm, sim, os mais altos números de estabelecimentos com SAFs (Desses, a porcentagem de agricultura familiar variou de 77 a $88 \%$ ). Parece haver uma tendência de os SAFs estarem em propriedades caracterizadas, então, como de agricultura familiar.

Todos os municípios apresentados nos Quadros 1 e 2 participaram de algum tipo de política pública voltada à agricultura familiar, com destaque principalmente ao PRONAF e ao PNAE.

Os valores financiados no PRONAF estão próximos dos 21 milhões de reais (Dados de 2015/2016) e os dados consultados apontam que as maiores porcentagens de adesão ao PNAE ocorrem em municípios com maior número de estabelecimentos com SAFs.

Embora não haja um detalhamento, pelo censo, dos modelos utilizados, muito provavelmente a escolha, alocação e distribuição regional dos modelos de SAF estão relacionadas a características agrossociais (HENKEL e AMARAL, 2008). Sabe-se que os modelos utilizados por agricultores abrangem desde modelos multiestratificados e altamente biodiversos até modelos mais simplificados que contemplam a inserção de espécies arbóreas exóticas em consórcios com poucas espécies.

Alguns sistemas já estão consolidados nos municípios em destaque ou nas regiões em que se inserem. Por exemplo, o Município de Dois Córregos tem apenas 13 estabelecimentos que totalizam 8012 ha com SAFs. A produção consorciada de café e de noz macadâmia tem sido um meio eficaz para aumentar os lucros de diversos produtores rurais na região em que se insere o município (SILVA , 2013). Já Mirante do Paranapanema tem uma expressiva quantidade de estabelecimentos com SAFs, em áreas pequenas, o que sugere que, provavelmente, estão presentes nos muitos assentamentos rurais que existem no município.

Mirante do Paranapanema e Presidente Prudente, no extremo Oeste, pertencem à região do Pontal do Paranapanema, que tem mais de 110 mil projetos de assentamentos rurais instalados. Nessa região, os SAFs têm sido utilizados para adequação ambiental, segurança alimentar e geração de renda nos lotes, e têm sido amplamente difundidos e estimulados por órgãos públicos que atuam na reforma agrária e na extensão rural na região. Mirante é o município com o maior número de assentamentos rurais, que são 34 (BARONE et al., 2011; LOPES et al., 2014). Geralmente, nessas áreas, são utilizados SAFs biodiversos, conhecidos como multiestratificados.

A região Centro-Oeste do Estado tem presença marcante de plantios de seringueira (municípios de Bauru, Avaí, Paraguaçu Paulista encontram-se nessa região). Essa espécie tem histórico de uso em modelos florestais e agroflorestais de produção (JúNIOR et al., 2007).

A microrregião de Capão Bonito e o oeste da microrregião de Registro pertencem ao trecho paulista da bacia hidrográfica do rio Ribeira de Iguape, conhecido por suas ricas características ambientais, sociais e culturais que vêm da combinação de diversas etnias e da grande preservação ambiental do local (DONATO e LIMA, 2014). É nesse contexto que os municípios se sobressaem quanto 
Distribuição de Sistemas Agroflorestais no Estado De São Paulo: apontamentos para restauração florestal e produção sustentável

ao número de estabelecimentos com SAF, estando categorizados em sua maioria na classe 3 (Figura 5).

\subsection{Sistemas agroflorestais para produção e restauração}

Os SAFs têm sido reconhecidos como um uso integrado da terra que pode contribuir com a agrobiodiversidade e com a conservação da biodiversidade em diferentes paisagens, além de aumentar, diversificar e sustentar a geração de renda em propriedades rurais (SWALLOW et al., 2006; SCHROTH et al. 2007). No Brasil, têm sido apontados como uma alternativa promissora para a restauração de áreas degradadas e reintrodução do componente arbóreo na paisagem rural (BRASIL, 2006; VIEIRA et al., 2009; MICCOLIS et al., 2011).

O número de SAFs e a área ocupada por eles eram relativamente pequenos em 2006, ano de aplicação do censo agropecuário no Estado de São Paulo. Apesar disso, há potencial para expansão dessas áreas e disseminação de modelos agroflorestais em função de mudanças ocorridas na legislação e de políticas públicas recentes, quer seja para a restauração de áreas degradadas, quer seja para a implantação de sistemas de produção voltados à adequação legal de propriedades rurais e, ainda, com utilização menor de insumos e mais sustentáveis do ponto de vista econômico e social.

De acordo com a legislação vigente, a manutenção e a restauração de cobertura florestal são obrigatórias em áreas definidas como áreas de preservação permanente e áreas de reserva legal (BRASIL, 2012). Em São Paulo, são consideradas prioritárias para restauração ecológica áreas relevantes para a conservação de recursos hídricos (incluindo áreas localizadas no entorno de nascentes e em Unidades de Gerenciamento de Recursos Hídricos com baixa cobertura vegetal nativa), áreas com elevado potencial de erosão e, ainda, que promovam o aumento da conectividade da paisagem regional, entre outras (SMA/SÃO PAULO, 2014).

Os SAFs são passíveis de utilização em projetos de restauração para adequação legal de propriedades rurais, principalmente - mas não somente naquelas descritas como pequena propriedade rural, e permitem o uso de ampla variedade de modelos, utilizando espécies exóticas e nativas, em áreas de reserva legal e de preservação permanente (BRASIL, 2012a; BRASIL, 2012b; SÃO PAULO, 2008). Em diversas situações, são apontados como a alternativa mais promissora de se unir conservação e produção (CALDEIRA e CHAVES, 2011).

Também no que se refere à adequação de assentamentos rurais à legislação, os SAFs têm sido testados e apontados como alternativas para a implantação em áreas de preservação permanente e de reserva legal, trazendo benefícios ecológicos e econômicos (BELTRAME et al., 2006; RODRIGUES et al., 2007; RODRIGUES et al., 2008; DARONCO et al., 2012; JUNQUEIRA et al., 2013).

Documentos recentes editados pela Secretaria de Estado do Meio Ambiente de São Paulo apontam que a distribuição dos estabelecimentos rurais deve ser considerada para a implantação de florestas nativas como atendimento à legislação. Em regiões com maior concentração de pequenas propriedades, os modelos sugeridos devem atender a demandas diferentes em relação a regióes com concentração de grandes propriedades. Para o órgão, a viabilização econômica de 
florestas nativas em reserva legal dependerá de uma espécie "carro-chefe", ou seja, aquela sobre a qual já haja conhecimento sobre silvicultura, cadeia produtiva e mercado com retorno financeiro (KUNTSCHIK, 2012). As duas espécies apontadas inicialmente como potenciais para serem utilizadas como carro-chefe (Hevea brasiliensis e Euterpe edulis - seringueira e palmeira jussara) têm histórico de utilização em consórcios e modelos agroflorestais.

Além delas, existem dezenas de espécies arbóreas nativas, fornecedoras de produtos florestais madeireiros e não madeireiros, passíveis de serem utilizadas em modelos agroflorestais nas áreas de cobertura original da Mata Atlântica, muitas das mesmas de ocorrência regional nas fitofisionomias presentes em São Paulo (CARVALHAES et al., 2008; SOUZA et al., 2010; OLIVEIRA e CARVALHAES, 2016).

Também culturas agrícolas perenes, já com cultivo estabelecido em muitas regiões e municípios, são passíveis de utilização nos SAFs, como laranja, manga, banana e café. $O$ mesmo pode-se dizer de espécies arbóreas exóticas, como a seringueira, a macadâmia e o eucalipto. Os consórcios de espécies arbóreas exóticas e nativas são permitidos para o manejo de áreas de reserva legal (BRASIL, 2012a), incluindo modelos agroflorestais de uso múltiplo.

Se forem consideradas somente as áreas de reserva legal, aproximadamente $20 \%$ da paisagem rural de São Paulo deveria incluir modelos de recomposição e restauração utilizando espécies arbóreas nativas (BRASIL, 2012a), o que torna os SAFs ainda mais atraentes.

Nessas áreas, características como tamanho das propriedades, presença/ausência de vegetação nativa, existência de áreas rurais consolidadas, modelo de produção (agricultura familiar ou não) e município em que se localiza o imóvel vão definir o tamanho da reserva legal-RL, e direcionar a escolha dos modelos (florestais e/ou agroflorestais) a serem instalados, e os métodos de restauração e espécies a serem utilizados, o que inclui também as características regionais e de preferência por produtores rurais.

\section{Conclusões}

O método adotado no software QGIS para o grupamento das variáveis analisadas por intervalos iguais permitiu o trabalho em diferentes escalas, sem interferência do arranjo dos dados. Isso permite comparações e uma caracterização em diferentes escalas, desde que seja levada em conta a amplitude dos conjuntos de dados em cada análise.

A análise da espacialização de áreas ocupadas com sistemas agroflorestais no Estado de São Paulo, para a escala de município, demonstra um uso ainda incipiente desses sistemas à época em que foi feito o Censo. Isso provavelmente está associado à concentração de assentamentos rurais e pequenas propriedades, à alta incidência de propriedades descritas como de agricultura familiar, à adequação de áreas de preservação permanente e reservas legais e ainda à possibilidade de implantação de modelos agroflorestais de produção com algumas espécies (principalmente exóticas) em particular.

Alterações recentes na legislação e desenvolvimento de políticas públicas voltadas à paisagem rural (com destaque àquelas voltadas à agricultura familiar), com vistas principalmente à restauração e conservação florestal e à produção 
Distribuição de Sistemas Agroflorestais no Estado De São Paulo: apontamentos para restauração florestal e produção sustentável

agrícola sustentável, geram a expectativa de que, nos próximos levantamentos, aponte-se um aumento significativo dos SAFs no Estado de São Paulo.

\section{REFERÊNCIAS}

ABDO, M. T. V. N. et al. Implantação de sistema agroflorestal com seringueira, urucum e acerola sob diferentes manejos. Pesquisa \& Tecnologia, vol. 9, n. 2, p. 1-15, jul-dez 2012. Disponível em: http://www.aptaregional.sp.gov.br/acesse-os-artigospesquisa-e-tecnologia/edicao-2012/julho-dezembro-2/1327-implantacao-de-sistemaagroflorestal-com-seringueira-urucum-e-acerola-sob-diferentes-manejos/file.html. Acesso em: 5 dez. 2016.

BARONE, L. A.; MELAZZO, E. S.; SILVA, A. A. (Coord) Cédula do Pontal do Paranapanema - acompanhamento e informação para o desenvolvimento rural. Relatório Anual MDA, 2011. 116 p. Disponível em: http://sit.mda.gov.br/download/ra/ra073.pdf. Acesso em: 5 dez. 2016.

BELTRAME, T. V. et al. Sistemas agroflorestais na recuperação de áreas de reserva legal: um2 estudo de caso no Pontal do Paranapanema, São Paulo. Revista Brasileira de Agroecologia, v. 1, n.1, p. 189-193. 2006. Disponível em: http://www.aba-agroecologia.org.br/revistas/index.php/cad/article/view/1493/1334. Acesso em: 5 dez. 2016.

BRASIL (a). Lei $n^{\circ} 12.651$, de 25 de maio de 2012. Dispõe sobre a proteção da vegetação nativa; altera as Leis $n^{\circ}$ s 6.938, de 31 de agosto de 1981, 9.393, de 19 de dezembro de 1996, e 11.428, de 22 de dezembro de 2006; revoga as Leis $n^{\circ} \mathrm{s} 4.771$, de 15 de setembro de 1965, e 7.754, de 14 de abril de 1989, e a Medida Provisória $n^{\circ}$ 2.166- 67, de 24 de agosto de 2001; e dá outras providências. 2012. Disponível em: <http://www.planalto.gov.br/ccivil_03/_ato2011-2014/2012/lei/l12651.htm > Acesso em: 21 jun. 2016.

BRASIL(b).Decreto $n^{\circ} 7.830$, de 17 de outubro de 2012. Dispõe sobre o Sistema de Cadastro Ambiental Rural, o Cadastro Ambiental Rural, estabelece normas de caráter geral aos Programas de Regularização Ambiental, de que trata a Lei no 12.651, de 25 de maio de 2012, e dá outras providências. 2012. Disponível em: <http://www.planalto.gov.br/ccivil_03/_Ato2011-2014/2012/Decreto/D7830.htm> Acesso em: 09 ago. 2016.

BRASIL. Ministério do Meio Ambiente, Ministério da Agricultura, Pecuária e Abastecimento, Ministério do Desenvolvimento Agrário, Ministério da Ciência e Tecnologia. Plano Nacional de Silvicultura com espécies nativas e sistemas agroflorestais. Brasília, 2006. 38 p.

BRASIL. Casa Civil. Secretaria Especial de Agricultura familiar e do Desenvolvimento Agrário. Relatórios para Brasil e Semiarido, Regiões, Estados, Territórios e Municípios. 2015. Disponível em: < 
http://www.mda.gov.br/sitemda/pagina/acompanhe-a\%C3\%A7\%C3\%B5es-do-mda-eincra> Acesso em: 20 dez. 2017.

BRITO, M. A.; COELHO, M. F. B. Os quintais agroflorestais em regiões tropicaisunidades auto-sustentáveis. Revista Agricultura Tropical, Cuiabá-MT, v. 1, n. 4, p. 738, 2000.

CARVALHAES, M. A. et al. Non-timber and timber forest products from Brazilian Atlantic Forest: opportunities for forest restoration and conservation. Florestar Estatístico, v. 11, n. 20, p. 9-17. 2008.

COELHO, G.C. Sistemas agroflorestais. São Carlos: Rima Editora, 2012. 184p.

COSTA, B. A. L.; AMORIM JUNIOR, P. C. G.; SILVA, M. G. As cooperativas de agricultura familiar e o mercado de compras governamentais em Minas Gerais. RESR, Piracicaba:, v. 53, n. 01, 2015, p. 109-126. DOI: http://dx.doi.org/10.1590/123456781806-9479005301006

COSTANTIN, A. M. Quintais Agroflorestais na visão dos agricultores de Imaruí-SC. Programa de Pós-Graduação em Agroecossistemas. 2005. 120f. Dissertação de Mestrado (Programa de Pós-Graduação em Agroecossistemas) - Universidade Federal de Santa Catarina, Florianópolis:, 2005.

DARONCO, C.; MELO, A. C. G.; MACHADO, J. A. R. Consórcio de espécies nativas da floresta estacional semidecidual com mandioca (Manihot sculenta Crantz) para restauração de mata ciliar. Revista Árvore, v. 36 n 2, p. 291-299. 2012.

DONATO, L.; LIMA, M. G. Distribuição geográfica do sistema agroflorestal na região do Vale do Ribeira. Geografia (Londrina) v.22, n.3. p. 47-64, set/dez. 2014.

ENGEL, V. L. Introdução aos sistemas agroflorestais. Botucatu: FEPAF, 1999. 70 p.

HENKEL, K.; AMARAL, I. G. M. Análise agrossocial da percepção de agricultores familiares sobre sistemas agroflorestais no nordeste do estado do Pará, Brasil. Bol. Mus. Para. Emílio Goeldi. Ciências Humanas, Belém, v. 3, n. 3, p. 311-327, dez. 2008.Disponível em <http://scielo.iec.pa.gov.br/scielo.php?script=sci_arttext\&pid=S1981$81222008000300003 \&$ Ing=pt\&nrm=iso $>$. Acesso em: 12 dez. 2016.

IBGE - Instituto Brasileiro de Geografia e Estatística. Base Cartográfica Contínua do Brasil, ao Milionésimo - Bcim. $4^{\mathrm{a}}$ versão, 2014. Disponível em: http://downloads.ibge.gov.br/downloads_geociencias.htm. Acesso em: 8 ago. 2016.

IBGE - Instituto Brasileiro de Geografia e Estatística. Censo Agropecuário 2006: resultados preliminares. Rio de Janeiro, p.1-146, 2007. Disponível em: http://biblioteca.ibge.gov.br/visualizacao/periodicos/49/agro_2006_resultados_preli minares.pdf. Acesso em: 8 ago. 2016. 
Distribuição de Sistemas Agroflorestais no Estado De São Paulo: apontamentos para restauração florestal e produção sustentável

JÚNIOR, W. L.; WISCH, E. N.; FRANCO, F. S. Desenvolvimento de sistema agroflorestal com seringueira no Oeste do Estado de São Paulo. Revista Científica Eletrônica de Engenharia Florestal, n. 3, p. 1-4, fev. 2004. Disponível em: http://faef.revista.inf.br/imagens_arquivos/arquivos_destaque/WneN3T4Aqp3B3eP_ 2013-4-24-15-27-2.pdf. Acesso em: 5 dez. 2016.

JÚNIOR, W. L. et al. Desenvolvimento de sistema agroflorestal com seringueira no Oeste do Estado de São Paulo. Revista Científica Eletrônica de Engenharia Florestal, n. 9, p. 1-7, fev. 2007. Disponível em:

http://faef.revista.inf.br/imagens_arquivos/arquivos_destaque/hglsBG9SMCB7LR2_2 013-4-26-12-16-34.pdf. Acesso em: 5 dez. 2016.

JUNQUEIRA, A. C.et al. Sistemas agroflorestais e mudanças na qualidade do solo em assentamento de reforma agrária. Revista Brasileira de Agroecologia, n. 8 v. 1, p. 102-115. 2013.

KRONKA, F.J.N. et al.. Inventário Florestal da Vegetação Natural do Estado de São Paulo. São Paulo, Secretaria do Meio Ambiente / Instituto Florestal / Imprensa Oficial. 2005. 200p.

KUNTSCHIK, D. P. Propostas para subsidiar um plano de implantação de florestas nativas com viabilidade econômica e ecológica. Instituto de Pesquisas e Estudos Florestais; Coordenadoria de Biodiversidade e Recursos Naturais da Secretaria de Estado de Meio Ambiente da SMA/SP. 2012. 44 p. Disponível em:<http://www.ipef.br/pcsn/documentos/relatorio_sintese_workshoppreliminar.pdf> Acesso em: 21 jun. 2016.

LOPES, P. R.; KAGEYAMA, P. Y.; LOPES, K. C. S. A. Sistemas agroflorestais e produção agroecológica de café na região do Pontal do Paranapanema. Retratos de Assentamentos, v.17, n.1, p. 261-292.2014.

LUNZ, A. M. P. Quintais agroflorestais e o cultivo de espécies frutíferas na Amazônia. Rev. Bras. de Agroecologia, v. 2, n. 2, p. 1255-1258, 2007.

MARTINEZ, G. B.; JÚNIOR, M. M.; JÚNIOR, S. B. Seleção de ideótipos de espécies florestais de múltiplo uso em planícies fluviais do Baixo Amazonas, Pará. Acta Amazonica, v. 40, n. 1, p. $65-74.2010$.

MAY, P.; TROVATTO, C. M. M. (Eds.). Manual Agroflorestal para a Mata Atlântica. Brasília: Ministério do Desenvolvimento Agrário. 2008. p. 195.

MICCOLIS, A. et. al. Políticas públicas e sistemas agroflorestais: lições aprendidas a partir de cinco estudos de caso no Brasil. In: PORRO, R. et al. (Org) Políticas públicas para o desenvolvimento agroflorestal no Brasil. Belém: ICRAF, p. 1-24, 2011. 
MONTAGNINI, F. Sistemas agroflorestales: principios y aplicaciones em los tropicos. San José: Organization for Tropical Studies, 1992. 622p.

MONTAGNINI, F. et al. Environmental services of native tree plantations and agroforestry systems in Central America. Journal of Sustainable Forestry, v. 21, n. 1, p. 51-67, 2005.

NAIR, P.K.R. An introduction to agroforestry. Dordrecht. Boston: Kluwer Academic Publishers/ICRAF, 1993. 499 p.

OLIVEIRA, R. E.; CARVALHAES, M. A. Agroforestry as a tool for restoration in Atlantic Forest: can we find multipurpose species? Rio de Janeiro: Oecologia australis, v. 20, n. 4, 2016. p. 425-435.

OLIVEIRA, R. E. et al. Aspectos da recuperação e uso de florestas em propriedades e paisagens rurais no Estado de São Paulo. In: Secretaria de Estado do Meio Ambiente. Recuperação Florestal: um olhar social. São Paulo: Imprensa Oficial, 2008. p. 45-78.

OLIVEIRA, R. E.; SAIS, A. C. Análise de instrumentos jurídicos para áreas de reserve legal em São Paulo: 2001 a 2016. Espacios, Caracas, v. 38, n. 41, 2017, p. 31 a 44.

PRINSLEY, R. The role of trees in sustainable agriculture - an overview. Agroforestry Systems, v. 20, n. 1, p. 87-115, 1992.

RODRIGUES, E. R. et al. O uso do sistema agroflorestal Taungya na restauração de reservas legais: indicadores econômicos. Floresta, Curitiba , v. 38, n. 3, p. 517-525, 2008.

RODRIGUES, E. R. Avaliação econômica de sistemas agroflorestais implantados para recuperação de reserva legal no Pontal do Paranapanema, São Paulo. Revista Árvore, Viçosa, v. 31, n. 5, p. 941-948, 2007.

SALAM, M. A.; NOGUCHI, T.; KOIKE, M. Understanding why farmers plant trees in the homestead agroforestry in Bangladesh. Agroforestry Systems, v. 50, p. 77-93, 2000.

SCHROTH, G. et al. Agroforestry and biodiversity conservation in tropical landscapes. Washington: Island Press, 2007. 537 p.

SILVA, I. C. Sistemas agroflorestais - conceitos e métodos, Itabuna: SBSAF, 2013, $308 \mathrm{p}$.

SIMMONS, C. S.; WALKER, R. T.; WOOD, C. H. Tree planting by small producers in the tropics: a comparative study of Brazil and Panama. Agroforestry Systems, v. 56, n. 2, p. 89-105.2002. 
Distribuição de Sistemas Agroflorestais no Estado De São Paulo: apontamentos para restauração florestal e produção sustentável

SMA - Secretaria de Meio Ambiente do Estado de São Paulo.Resolução SMA n ${ }^{\circ} 2$, de 03 de abril de 2014. Estabelece as orientações, diretrizes e critérios sobre restauração ecológica no Estado de São Paulo, e dá providências correlatas. Disponível em: <http://www.ambiente.sp.gov.br/legislacao/resolucoessma/resolucao-sma-32-2014/> Acesso em: 21 jun. 2016.

SOMMARIBA, E. Revisiting the past: an essay on agroforestry definition. Agroforestry Systems, v. 19, n. 3, p. 233-240, 1992.

SOUZA, M. C. S.; PIÑA-RODRIGUES, F. C. M. Desenvolvimento de espécies arbóreas em sistemas agroflorestais para recuperação de áreas degradadas na Floresta Ombrófila Densa, Paraty, RJ. Revista Árvore, Viçosa, v.37, n.1, p.89-98, 2013.

SOUZA, H. N. et. al. Selection of native trees for intercropping with coffee in the Atlantic Rainforest biome. Agroforestry Systems, v. 80, n. 1, p. 1-16, 2010.

SOUZA-ESQUERDO , V. F.; BERGAMASCO, S. M. P. P. Análise sobre o acesso aos programas de políticas públicas da agricultura familiar nos municípios do Circuito das Frutas (SP). RESR, Piracicaba, v. 52, 2015, p. 205-222.

STEENBOCK, W. et al (Org) Agrofloresta, Ecologia e Sociedade. Kairós, Curitiba, 2013, p. 321 a 344.

SWALLOW, B.; BOFFA, J.; SCHERR, S. J. The potential for agroforestry to contribute to the conservation and enhancement of landscape biodiversity. In: GARRITY, D. (Org). World Agroforestry into the Future. Nairobi: World Agroforestry Centre, 2006, p. 95 a 102.

VALENTINI, L. S. P. et al. Temperatura do ar em sistemas de produção com café arábica em monocultivo e arborizados com seringueira e coqueiro-anão na região de Mococa, SP. Bragantia, Campinas, v. 69, n. 4, p1005-1010, 2010.

VIEIRA, D. L. M.; HOLL, K. D.; PENEIREIRO, F. M. Agro-successional restoration as a strategy to facilitate tropical forest recovery. Restoration Ecology, v. 17, n. 4, p. 451459, 2009.

VIVAN, J. L. Pomar ou floresta: princípios para manejo de Agroecossistemas. Rio de Janeiro: AS-PTA, 1993. 96 p.

VIVAN, J. Agricultura e florestas: princípios de uma interação vital. Guaíba: Agropecuária, 1998. 207 p. 
Adriana Cavalieri Sais. Universidade Federal de São Carlos Departamento de Desenvolvimento Rural. acsais@cca.ufscar.br

Renata Evangelista de Oliveira. Universidade Federal de São Carlos Departamento de Desenvolvimento Rural. reolivei@cca.ufscar.br 